\title{
Decision Making with Multi Criteria through Hierarchic Analysis Technique and its Effect on Customer Decision Procedure
}

\author{
Alireza Shahraki ${ }^{1},{ }^{*}$ Hadi Zarea ${ }^{2}$, Abbas Jannesari $^{3}$ \\ ${ }^{1}$ University of Sistani and Baluchistan, Zahedan, I.R.Iran \\ ${ }^{2}$ University of Tehran, Tehran, I.R.Iran \\ ${ }^{3}$ University of azad, branch of zahedan, Zahedan, I.R.Iran \\ *zarea@alumni.ut.ac.ir
}

\begin{abstract}
Today, world competition situation is in a way that organizations need to increase the quality and increase the customer satisfaction, increase the benefit and decrease in outgoings, all at the sometime together. One side, goods prices increase and sever competition in market between goods, and on the other side, complexity in customers attitude and their vary expectations made disaster in management and share increase of the market. So, increase of effects on customer decision procedure as a new attitude in these situations born. Customer decision procedure is a kind of decision- making that is mode by the users. In general, decision-making is recognition processes through selection among different choices. How many criteria are used to analysis by the users? In addition, what kind of criteria do they consider? In addition, to what extent do they emphasize according to their favorites or goods importance. Hierarchic analysis procedure (AHP) is a decision-making with multi criteria that is suitable complex decisions, and consist of decision elements compare in where recognition of quality has encountered with problem. Ranking in decision choices of AHP is to solve the puzzle complexity AHP procedure by finding the specification through different choices, declare good buying decision.
\end{abstract}

Key words: Hierarchic Analysis Procedure, buyer decision-making procedure, buyer behavior

\section{Introduction}

Consumer buying behavior is very complex and to vary extent it may different in kind of goods and buying decision, consumers use different specifications and criteria in decision making, specially, assessment level. AHP is very tactful and useful for customer decision procedure assessment. Buying decision making procedure: to consumer, buying decision is an imagine of an individual that goes through details of goods package, brand and the services and by rational choice and least outgoing do its choice. Those who marketing ought to act over different effects on buyer's behavior, and develop their understanding about consumer behavior in decision-making. In addition, they should answer to questions such as: who made the decision to buy? What kind of buying do we have? What are the buying procedure levels? Market researchers build a buying decision-making procedure model. The users pass over five levels: recognition, searching the information, choices assessments, buying decision and the behavior after buying. Recognition: buying start when buyer recognizes a problem or need, and that could be instigated by the internal and external factors. Market-seekers should bring needs situation to market. By collecting the customer information, they can recognize the most popular factors that have brought favor to customer.

Search the information: An instigating customer eager to search more information. Number, size and effects of information sources different goods rank and buyer's specification, each information source remain different function in buy decision. Customer learns through collecting information about brand competitions and specifications. Choices assessment: vary procedure exist in decision assessment. The most popular model is seeing them as a recognizable. Through customer point of view, goods specifications are different, they consider the most suitable and the most important specifications and the most attention they do to their benefits. Buy decision: In assessment level, users choose among their trade brands, and their attention to buy will be among top brands. Others attitude and unpredictable situation elements also can have effects on buy. The behavior after buying: the users will experience some satisfaction or non-satisfaction levels, after buying. Market seekers ought to follow the users. Satisfaction, some action and the goods benefit grades after buying. 
Figure 1: Five-Stage Model of Consumer Buying

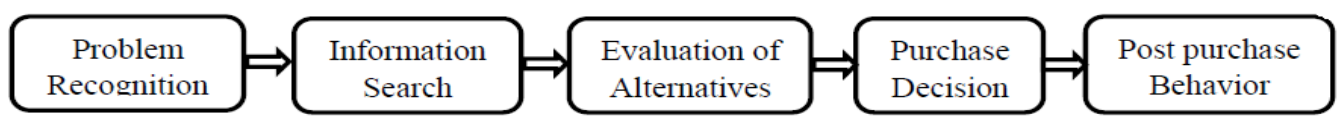

\section{Literature Review}

In 1977, Mr. Saaty introduced (AHP) as a multi criteria decision. AHP is a benefit way to make decision. In addition, many researchers accept it because of its mathematical specifications and being researchable in its internal data. AHP is a supporting tool for decision and can be helpful for unstructured decisionmaking and complex, and it can be done through multi levels hierarchic structure of aims, criteria, secondary criteria and choices. Some functional programs in industry engineering of AHP are: Complex productions, decision assessment about investing and innovation, reflex able production system, placement design, programming airport and international consulate terminals location, titan and complex project such as silorik, software development, delivery section, package of connection media and other engineering topics, all can help in different issues of decision-making. Narver and Slater (1990) suggest that, if organizations view their customers only as end-users, they may be less competitive than their counterparts who involve their customers in a variety of roles that expand and deepen the relationship. El Sawy et al. (1999) and Cronin and Taylor (1992) suggest that, to survive in demanding business environments, organizations need to innovate and invent new ways of creating value, and require different enterprise architectures and information technology (IT) infrastructures to meet customer demands. Because of the rapid advancement of IT, enterprises adopt customer-centric information system (IS) applications to transform themselves into customer-centric ARA 18, 3262 organizations. However, to sustain a competitive advantage, firms must go beyond simply applying technological tools and techniques to include a shift in values, assumptions, and premise (Soh et al., 2000), guiding all business activities towards understanding and fulfilling customer requirements. At the core of this orientation is the necessity for developing and establishing long-term relationships with customers, aimed at improving customer service and satisfaction.

Customer relationship management (CRM): CRM has emerged in recent years as the convergence of a number of factors. The impetus for the interest in CRM came from Reichheld (1996) and Best (2002), who hypothesized a dramatic increase in profits from small increases in customer retention rates. CLV, along with customer retention rate, customer attrition rate, customer loyalty, customer profitability, and customer satisfaction, have become key measures used to evaluate the effectiveness of CRM implementation among firms. Some companies view CRM primarily as an investment in technology and software, whereas others treat CRM more expansively and are aggressive in developing productive relationships with customers. These two perspectives of CRM merit separate discussion (Kotler, 2002).

Customer-related strategies: Blattberg and Deighton (1996) introduced the term CE, calculated as the net present value of cash flow generated from present and potential customers, to help managers to determine the optimal balance between acquisition and retention strategies for their particular companies. Blattberg et al. (2001) and Ness et al (2002) suggest that CE management is built around three core strategies: acquisition, retention, and add-on selling. In Blattberg and Deighton' (1996) and Blattberg et al.'s (2001) CE model, the authors indicate that there should be an interrelationship among these three strategies, so that the more efficient and effective the acquisition phase, the better are the add-on selling and retention programs. They also indicate that customer retention strategies have implications and influences for acquisition strategies, and that successful add-on selling to current customers can allow a firm to increase investment in new customer acquisition, since the cost of selling additional products to current customers is generally lower and thus profits are higher (Blattberg et al., 2001). Thomas (2001) emphasizes that failure to make correct acquisition and retention decisions will lead to inaccurate forecasts about how long a customer will stay the expected profitability of customers, and the impact of marketing efforts. She proposes a new methodology that studies customer retention while accounting for the impact of the acquisition process on the retention process, even when data on prospects are not available. Her model shows that failure to account for acquisition will give biased estimates of the duration of a relationship and will, therefore, bias any estimate of CE or CLV. In addition, she provides empirical support for the belief that the customer acquisition process affects the customer retention process. 


\section{Material and Way}

Hierarchic procedure theory - decision procedure has encountered several quality and quantity problems, for example, choosing a good car, if nice criteria, model, price, we can see problems like lack of standards to measure quantity criteria, lack of unit to convert criteria (quality and quantity) buy the way, attention to problems related decision procedure alongside multi criteria, complexity, lack of standard, to the very extent, decreased from speed and decision - making precise and made this procedure to be depended to the one who make decision. AHP is one the most comprehensive system designed with multi criteria. As we can formulate decision procedure, can consider quality and, enter decision choice to the problem, analyze the sensitivity of above and under the criteria and achieve adaptability and inadaptability of decision that is of top specifications. AHP is an organization based on rational that analysis problems in to small-consisted sections, decision-maker can focus on limited issues at that time. AHP is done in two levels: hierarchic design and assessment in main elements in hierarchic. AHP is a decision with multi criteria, especially suitable for complex decision. AHP as a sample of complex problem start like this:

- On the top of the hierarchic, aim is that could be taken best decision based on that.

- Next level of hierarchic consisted of adjectives or criteria that would help to the quantity of decision. Each category can be analyzed to more categories.

- The lowest level of hierarchic consists of decision choices.

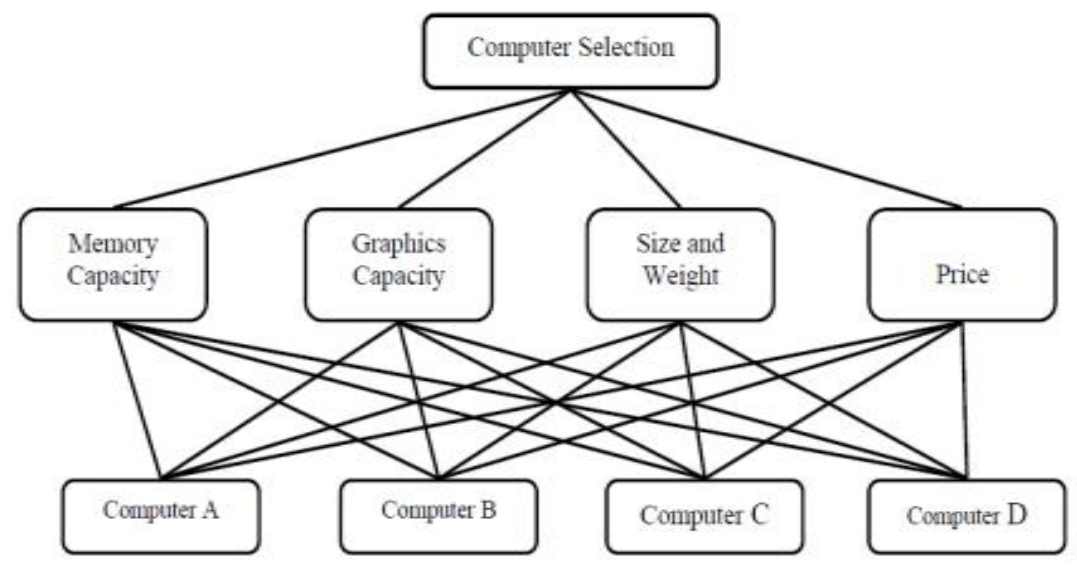

Figure 2: Evaluating Buyer Decision Process through AHP Model

When hierarchic network is done, then we can declare weight of elements in each level of hierarchic, and to mix weight we can declare weight of decision choices. First, a comparative matrix that first level consist of hierarchic criteria then a proportional compare out of pair compare of criteria is done in accordance with complete aim. Proportional importance of each criteria estimate with vector or other techniques. Then, the proportional importance of each choice is defined according to similar pair compare. Pair compares between criteria and between choices is done by dot compare. Suppose aij as a matrix A, AHP use missing link compare 1 to 9 that aij $=1$ shows that $\mathrm{j}$, I are at the equal importance, aij $=5$ shows that I is more important than $\mathrm{j}$ and aij $=9$ shows I is more important than $\mathrm{j}$. The other average value among 1 to 9 defines as an omniscient. Usually, an individual shape a triangle above comparative matrix when it has opposite below it. in other words, if we consider 5 for $(\mathrm{I}, \mathrm{j})$ matrix as a comparative factor, and image $\mathrm{I}, \mathrm{j}$ in the column and level of compare matrix , so I,j amount is 1,5. Also if each of these criteria being at the same importance, so matrix element always will be one. Pair comparative privilege is that it may encounter fewer mistakes. Adaptability concept in selection procedure in defined like this. If you choose $\mathrm{B}$ better than $\mathrm{C}$ and $\mathrm{C}$ better than $\mathrm{D}$, it means that $\mathrm{B}$ is better than D AHP difficulties are to define proportional weight for levels of choices.

Suppose $\mathrm{n}$ comes because of pre-defined comparative to shows the importance of the specifications. Right now, the present matrix $\left(\mathrm{n}^{*} \mathrm{n}\right)$ is normal and its weight is calculated like this: where ever $\mathrm{I}, \mathrm{j}$ is to compare, we can consider aij as an amount that shows comparative among choices or adjective I and $j$, the procedure that make $\mathrm{n}^{*} \mathrm{n}$ comparative matrix like A, reflect the decision - maker point of view about the importance of different criteria the compare is like each of criteria in lines $(i=1,2,3 \ldots . . . n)$ to each criteria will categorized. Proportional weight of each criterion means divide elements of each column to 
complete elements of that column. The outcome matrix called normal matrix N. The Belowmatrix may adapt if aij,Ajk= aik for all amounts $\mathrm{k}, \mathrm{j}, \mathrm{I}$ whole elements in one column yk= $\Sigma$ aij that $\mathrm{i}=1,2,3 \ldots . \mathrm{n}$ and $\mathrm{j}=1,2,3 \ldots . . \mathrm{n}$, the average $\mathrm{bk}=[(\mathrm{ak} 1) \cdot(\mathrm{ak} 2) \ldots(\mathrm{akn})] 1 / \mathrm{n}$ in which $\mathrm{k}=1,2, \ldots . . \mathrm{n}$ calculated. Normal weight calculate as $\mathrm{xk}=\mathrm{bk} / \Sigma$ bk. Specification or acceptability of each choice measured by (CR) consistency rote. (C1) and (CR) for A matrix will calculate as it comes: $\mathrm{CR}=\mathrm{c} 1 / \mathrm{R} 1$ produced stable indicator randomly $\mathrm{CI}=$ $(\lambda \max -n) /(n-1)$ when $\lambda \max$ has the biggest value in pair comparative matrix.

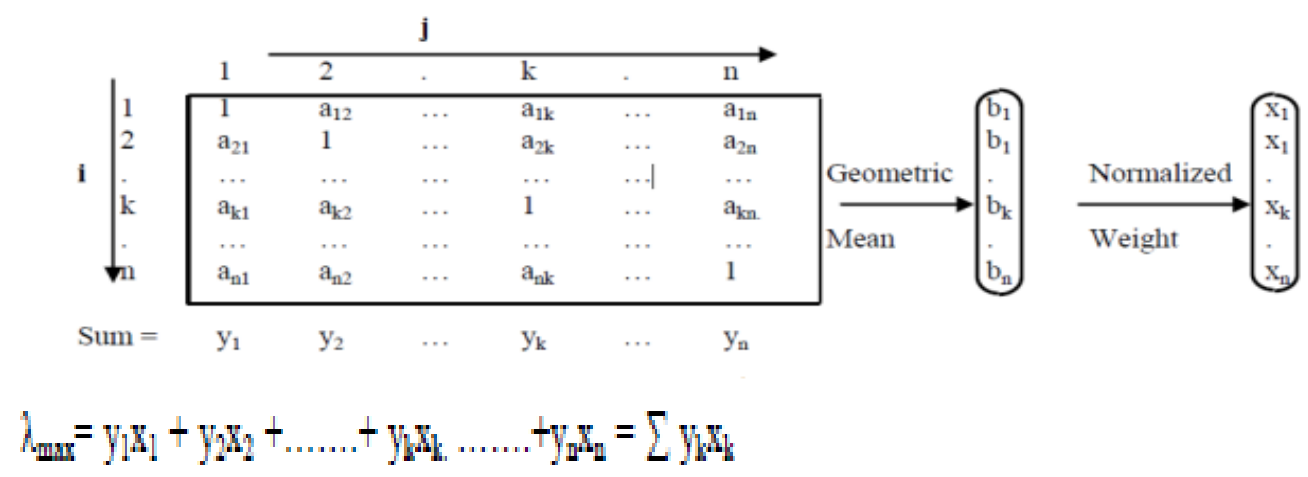

some produced stable indicator randomly (R1) is amount like this:

\begin{tabular}{|l|l|l|l|l|l|l|l|l|l|l|}
\hline $\mathrm{n}$ & 1 & 2 & 3 & 4 & 5 & 6 & 7 & 8 & 9 & 10 \\
\hline R. I. & 0 & 0 & 0.58 & 0.9 & 1.12 & 1.24 & 1.32 & 1.41 & 1.45 & 1.49 \\
\hline
\end{tabular}

If $\mathrm{CR}<10 \%$, paradox level is acceptable, otherwise it is rejected or should canceled. All indicators should measure accurately and precisely to be sure, about the selection right.AHP is the outcome of all attempts to reach to a systematic process about buy decision. Definition of problem: assessment let the users to know about brands features, now, imagine a user limit himself to four computer $(A, B, C, D)$ and image he is eager to all memory capacity, memory card capacity, size, weight and price, in the column that comes below we show his beliefs about the brand.

Table 2: A Computer's Brand Beliefs about Customers

\begin{tabular}{|c|c|c|c|c|c|}
\hline \multirow{2}{*}{ Computer } & \multicolumn{4}{|l|}{ Attributes } & \multirow{2}{*}{ Scores } \\
\hline & Memory Capacity & Graphics Capacity & Size and Weight & Price & \\
\hline A & 10 & 8 & 6 & 4 & 8.0 \\
\hline B & 8 & 9 & 8 & 3 & 7.8 \\
\hline C & 6 & 8 & 10 & 5 & 7.3 \\
\hline $\mathrm{D}$ & 4 & 3 & 7 & 8 & 4.7 \\
\hline Weight & 0.40 & 0.30 & 0.20 & 0.10 & \\
\hline
\end{tabular}

majority of buyers consider several factors their buy, imagine $40 \%$ for PC memory capacity, $30 \%$ for Graphic card capacity, $20 \%$ to size and weight and $10 \%$ to price allocated weight of each is its scores, finally, all summarized to score for products. Therefore A pc $(8$, score) is the highest value to user. In addition, its limitation is that we cannot assess the quantity of criteria. (It is our problem) memory capacity, card capacity weight size, price all are depended to each other closely. However, it did not consider above but it can be corrected if we mix to AHP. That we call it, (MCDM) multi criteria Decision making.

\section{Conclusion}

Assessment through AHP: hierarchic analysis procedure is a technique to MCDM that we consider both quality and quantity function to select a choice. Buyer decision consisted of several quantity and quality criteria. Quality criteria will be judged by the experts view while quantity criteria will be calculated by collected data. The above example through hierarchic analysis procedure is assessed increase buy 
decision-making procedure affects with choices assessment and with quality and quantity factors. For example, if users believe memory capacity in average is more important than price, so it scoters 3.These compares are accessory to all criteria and choices. The user to define proportional importance of criteria to complete matrix should develop a paired comparative package. Some level of preference weight for AHP comes below:

Table 14: Final Evaluation for Analytic Hierarchy Process (AHP)

\begin{tabular}{|c|c|c|c|c|c|c|}
\hline \multirow{3}{*}{ Alternatives } & \multicolumn{4}{|c|}{ Attributes and their Weights } & \multirow{3}{*}{$\begin{array}{c}\text { Composite } \\
\text { Weight }\end{array}$} & \multirow{3}{*}{$\begin{array}{l}\text { Over-al } \\
\text { Ranking }\end{array}$} \\
\hline & $\begin{array}{l}\text { Memory } \\
\text { Capacity }\end{array}$ & $\begin{array}{l}\text { Graphics } \\
\text { Capacity }\end{array}$ & $\begin{array}{l}\text { Size and } \\
\text { Weight }\end{array}$ & Price & & \\
\hline & 0.43017 & 0.23488 & 0.06009 & 0.27486 & & \\
\hline Computer A & 0.389817 & 0.285695 & 0.193543 & 0.199985 & 0.301389 & 1 \\
\hline Computer B & 0.220365 & 0.321477 & 0.258061 & 0.149998 & 0.227038 & 3 \\
\hline Computer C & 0.233879 & 0.285695 & 0.32257 & 0.250009 & 0.255812 & 2 \\
\hline Computer D & 0.155939 & 0.107132 & 0.225826 & 0.400008 & 0.215759 & 4 \\
\hline
\end{tabular}

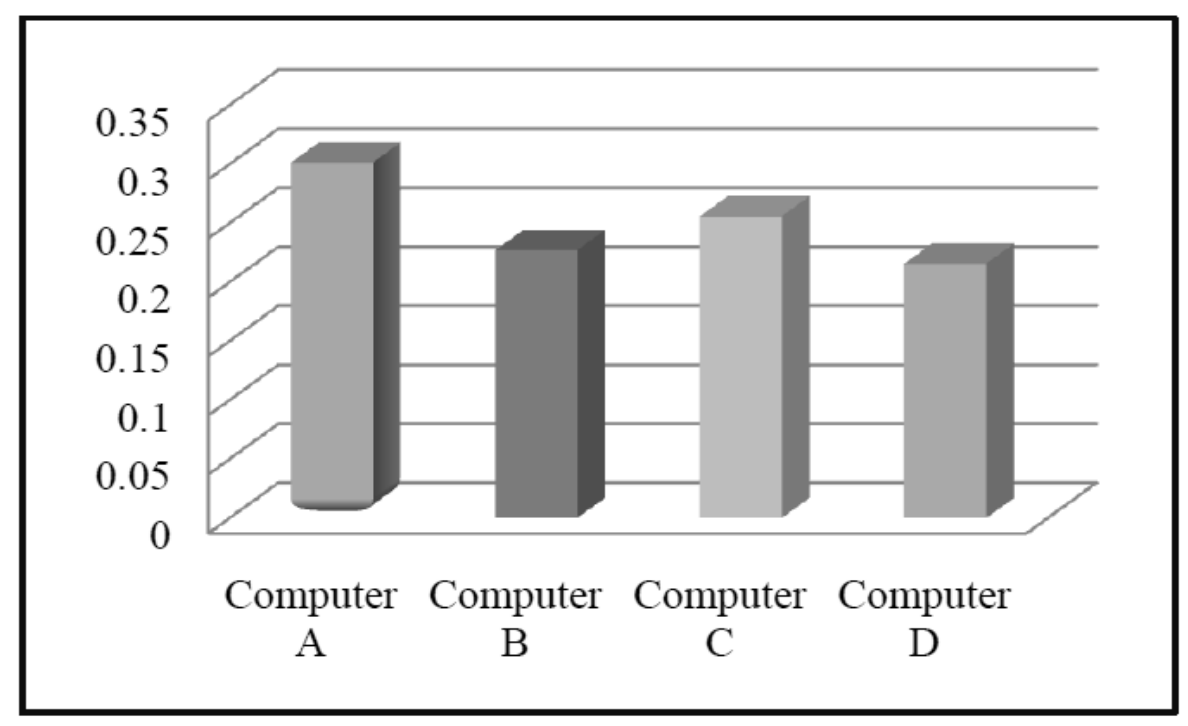

Figure 3: Decision Analysis Graph

One of the ways to entering into market is that know consumers behavior and their criteria so, buying procedure analysis is done long time before buying and long time after buying in continues. Choices assessment is a vital and criteria level of buying procedure. Hierarchic analysis procedure could be of individual advocate. In this article decision -making procedure explained with criteria and assure and guarantee that an effective buying decision can be reachable through finding effective specifications of different choices alongside considering both quality and quality function. 


\section{References}

Best, R. J. (2002). Market-based Management, Prentice-Hall, Upper Saddle River, NJ.

Blattberg, R. C. \& Deighton, J. (1996). Manage marketing by the customer equity test. Harvard Business Review, 74(4), 136-44.

Blattberg, R. C., Getz, G. \& Thomas, J. S. (2001). Customer Equity: Building and Managing Relationships as Valuable Assets, Harvard Business School Press, Boston, MA.

Cronin, J. J. \& Taylor, S. A. (1992). Measuring service quality: a reexamination and extension. Journal of Marketing, 56(3), 55-68.

El-Sawy, O. A., Malhotra, A., Gosain, S. J. \& Young, K. M. (1999). IT-intensive value innovation in the electronic economy: insights from Marshall Industries. MIS Quarterly, 23(3), 305-35.

Kotler, P. (2002). Marketing Moves: A New Approach to Profits, Growth and Renewal, Harvard Business School Press, Boston, MA.

Narver, J. C. \& Slater, S. F. (1990). The effect of a market orientation on business profitability. Journal of Marketing, 54(4), 20-35.

Ness, J. A., Schroeck, M. L., Letendre, F. R. \& Douglas, W. J. (2002). CRM and customer lifetime value. Cost Management Update, 132, 1-2.

Reichheld, F. F. (1996). The Loyalty Effect, Harvard Business School Press, Boston, MA.

Soh, C., Kien, S. S. \& Tay-Yap, J. (2000). Cultural fits and misfits: is ERP a universal solution? Communications of the ACM, 43(4), 47-51.

Saaty, T. L. (1977). A Scaling Method for Priorities in Hierarchical Structures. Journal of Mathematical Psychology, 15, 57-68.

Thomas, J. S. (2001). A methodology for linking customer acquisition to customer retention. Journal of Marketing Research, 38(2), 262-68. 